\title{
Current directions in searching for tuberculostatic substances
}

\author{
Justyna Żwawiak, Lucjusz Zaprutko \\ Department of Organic Chemistry, Poznan University of Medical Sciences, Poland
}

\begin{abstract}
Yearly, 8 milion people advance to active tuberculosis (TB) and nearly 2 milion victims die of their infection. Long drug regimen is blamed for the emergence of drug resistant TB. Moreover, $20 \%$ of TB isolates are already resistant to the first line antituberculosis drugs. This situation has required to develop new, more active anti-TB substances. Several novel drug candidates from different groups of chemical compounds undergo clinical trials. Others, also promising agents, have been obtained recently. They are the basis for further modifications heading for improvement of their physicochemical, biological and toxicological parameters.
\end{abstract}

Key words: tuberculosis, tuberculostatic agents, clinical trials.

It is a very complex process to develop and introduce new drugs, requiring years of hard work and large expenses. It often takes 12-15 years from qualifying a substance to clinical tests to their successful completion. What is also important is that only $10 \%$ of substances qualified to clinical tests reach the end of the study with positive notes. There are a few new tuberculostatic drugs of various chemical composition being currently in different clinical trial phases $[1,2,3]$. Virtually no new effective tuberculostatic drugs appeared on the pharmaceutical market since rifampicin has been introduced (1970). In the meantime, new multidrug-resistant bacterial strains have evolved, making the antituberculotic treatment even harder. That is why it is necessary to search for new substances with different antituberculotic effects. In the next few years, there should be at least a few new and effective drugs of that kind. The tested drugs include: two bicyclic nitroimidazole derivatives: PA-824 and OPC-67683 [4], a pyrrol derivative LL- 3858 and some quinoline derivatives. From the beginning of the $21^{\text {st }}$ century, a lot of new substances were identified that stand chances to become some of leading tuberculostatic drugs. Some of them are already being tested, and others, equally promising, have been discovered recently and are still subject to further research to improve their physicochemical, biological and toxicological properties.
This study will try to present the most interesting and promising tuberculostatic substances that have been reported in scientific news in the last twelve years.

At present, one of the diarylquinoline-type substances named TMC-207 (R-207910) has successfully undergone the second trial phase. This is one of the most promising tuberculostatic drugs. It will probably become a part of multi-drug therapy against multidrug-resistant $M$. tuberculosis strains. There are twenty chemical substances in the diarylquinoline group, with MIC values below $0.5 \mu \mathrm{g} / \mathrm{ml}$ in in vitro studies on $M$. tuberculosis H37Rv. Antituberculotic effect was confirmed in vivo for three diarylquinoline combinations [5]. The one with the most advantageous characteristics was chosen, named TMC-207 and had undergone a number of further tests. This compound turned out to be an in vitro $M$. tuberculosis growth inhibitor for strains susceptible to the most common drugs as well as drug-resistant strains [6]. Its activity in in vivo tests was stronger than the activity of rifampicin and isoniazide and, furthermore, it was effective against latent bacterial forms. The antituberculotic effect increased when rifampicin, isoniazide and pyrazynamide were replaced by diarylquinoline TMC-207 (R-207910), leading to total bacilli elimination within two months of treatment. Moreover, this compound has a new 
mechanism of action - it is a proton pump inhibitor of a $\mathrm{F}_{0} \mathrm{~F}_{1} \mathrm{H}^{+}$ATP-synthase, which leads to a damage of the ATP structure and acid-base balance disorders in bacterial cells.

The tuberculostatic effect was also observed in 4-amine-7-chloroquinoline derivatives [7]. The strategy for obtaining these compounds was based on a substitution of chlorine atom in C-4 position in a 4,7-dichloroquinoline molecule by ethylenediamine chain, which is an ethambutol pharmacophor, and subsequently by its homologues: propylene- and butylenediamine and so on. The objective of further modifications was to determine the Structure-Activity Relationships (SAR) for the obtained products. It was observed in in vitro tests that in a group of 4-amine-7-chloroquinoline derivative compounds with different substituents in terminal carbon atom of alkyl chain, the most active compound was the one with a chlorine atom (MIC $=12.5 \mu \mathrm{g} / \mathrm{ml}$ ). The MIC value changed adversely after substitution of halogens with amine group $-\mathrm{NH}_{2}$ or azide group $-\mathrm{N}_{3}$. The effect of the alkyl substituent length on antituberculotic effect was also tested. It turned out that lateral chain elongation up to ten carbon atoms leads to an increased tuberculostatic effect (Figure 1).

Another prospective antituberculotic drug is a substance identified as SQ-109. This compound was singled out of a group of 63,000 diamines in a search for antituberculotic substances [8-11]. This substance's mechanism of action inhibits the cell wall formation in tubercle bacilli. In the in vitro conditions, SQ-109 has even 35 times stronger tuberculostatic effect compared to another diamine group member, ethambutol. This substance is also effective against multidrug-resistant microbes. Adding SQ-109 to rifampicin and isoniazid in antituberculous therapy makes the latter ones more effective. Different tests assessing efficacy of SQ-109 and other antituberculotic drugs combinations as well as SQ-109 monotherapy treatment are currently being conducted. Apart from antituberculotic effect, this sub- stance is effective also against Helicobacter pylori. This effect is now being tested and is in the second phase of clinical trials [12].

Further search for new, better antituberculous drugs yielded a discovery of the group of $\beta$-sulphonylacetamide compounds. One compound with the highest activity was selected out of this group and marked FAS-20013. It has been proved that this substance is a mycolic acid synthase inhibitor and that it disturbs energy production in bacterial cells, causing their systematic dying. FAS-20013 is also effective in the case of drug resistance. Moreover, this drug was observed to cause no serious adverse effects [13, 14] typical of other similar drug classes.

Sutezolid, initially marked as PNU-100480, is an oxazolidinone antibiotic currently in the second phase of clinical trials. Sutezolid is three times more active against MDR-Tb strains than structurally similar linezolid, both in vivo and in vitro. Compared to linezolid, it is much less toxic and has better pharmacokinetic characteristics resulting from drug absorption. Mechanism of action for both oxazolidinones consists in binding the 505 subunit of the ribosome, and thus inhibiting one of the earliest stages of essential bacterial proteins synthesis [15].

It was observed in another study that some of pyrrole derivatives have a tuberculostatic effect on $M$. tuberculosis in in vitro conditions. The most active compound - LL-3858 has been selected out of this group and is characterized by being more effective in monotherapy than isoniazide in vivo. The mean MIC value is $0.19 \mu \mathrm{g} / \mathrm{ml}$, also for drug-resistant strains [16]. Its mechanism of action has so far remained unknown.

Chemical structures of the described compounds are displayed in Figure 2.

Pleuromutiline belongs to the class of semisynthetic antibiotics, produced from Pleurotus mutilis strains. Two members of that class, tiamulin and valnemulin, are veterinary antibiotics acting against avian myco-<smiles>[R]C(C)(C)CCNc1ccnc2cc(Cl)ccc12</smiles>

\author{
$\mathrm{R}=-\mathrm{NH}_{2}$ \\ $\mathrm{n}=6 \quad \mathrm{MIC}=25.0 \mu \mathrm{g} / \mathrm{ml}$ \\ $\mathrm{n}=8 \quad \mathrm{MIC}=6.25 \mu \mathrm{g} / \mathrm{ml}$ \\ $\mathrm{n}=10 \quad \mathrm{MIC}=3.12 \mu \mathrm{g} / \mathrm{ml}$
}

$\mathrm{R}=-\mathrm{H},-\mathrm{NH}_{2},-\mathrm{OH}$, halogen, $-\mathrm{N}_{3}$, etc.

Figure 1. The MIC values for quinoline derivatives against M. tuberculosis 


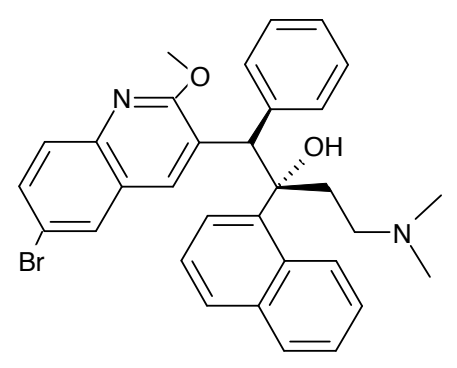

TMC-207 (R-207910)

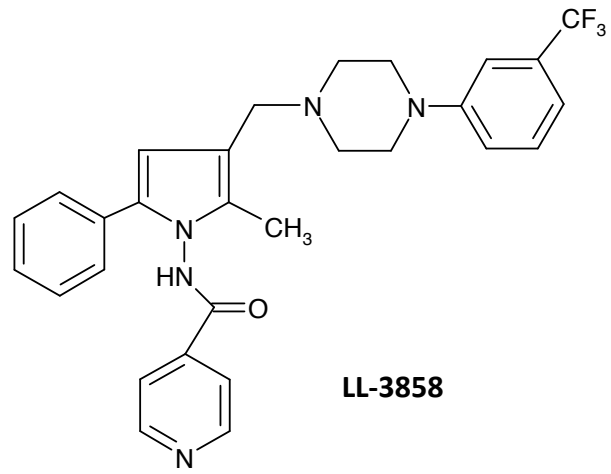<smiles>CCCCCCCCCCS(=O)(=O)CC(N)=O</smiles>

SQ-109

FAS-20013

\section{Sutezolid}<smiles>CCCCC(C)(C)OC(=O)OCCCCCCOc1ccc(N2CCC(Oc3ccc(OC(F)(F)F)cc3)CC2)cc1</smiles><smiles>O=[N+]([O-])c1cn2c(n1)OCC(OCc1ccc(OC(F)(F)F)cc1)C2</smiles>

PA-824

Figure 2. The structures of choosen tuberculostatic agents currently undergoing clinical trials

plasmosis. Pleuromutilines inhibit bacterial protein synthesis by binding the 505 subunit of the bacterial rRNA and thus inhibiting formation of peptidic bonds [17]. This mechanism of action suggested a possibility of using these antibiotics in antituberculotic treatment. Further studies proved these antibiotics to have antituberculotic effects, also against drug-resistant strains. Chemical structures of these substances are shown in Figure 3.

While searching for new antituberculotic drugs, previously known antibiotic classes were re-analyzed. Two fluoroquinolones were found that way: gatifloxacin (GAT) and moxifloxacin (MXF) [18]. Both drugs are now in the third phase of clinical trials. Gatifloxacin has a tuberculostatic effect in vitro as well as in vivo. In in vitro tests, the greatest antituberculotic effect is observed during the first two days of testing [19]. Similar results were obtained when gatifloxacin was used in combination with isoniazide (INH) or rifampicin (RIF) [19]. The other tuberculostatic drug in the fluoroquinolone class, moxifloxacin, is more promising. In in vitro conditions, it destroys populations of tubercle bacilli which developed resistance to rifampicin. This distinguishes moxifloxacin among other tuberculostatic fluoroquinolones of prior generations: ciprofloxacin and ofloxacin [18]. It is likely that moxifloxacin influences protein synthesis in slow metabolizing bacteria. This mechanism significantly differs from rifampicin's 
<smiles></smiles>

Figure 3. The structures of choosen pleuromutilins<smiles>[R]c1cccc(NC(=S)N(C)/N=C\c2ccc([N+](=O)[O-])o2)c1</smiles>

Tiamulin: $\mathrm{R}=$

Walnemulin: $\mathrm{R}=$<smiles>CCN(CC)CC</smiles><smiles>CC(C)C(N)C(=O)NCC(C)(C)C</smiles>

\begin{tabular}{ccc}
\hline $\mathbf{R}$ & $\mathbf{X}$ & $\mathrm{MIC}(\boldsymbol{\mu g} / \mathbf{m l})$ \\
\hline $\mathbf{3}-\mathbf{B r}$ & $\mathrm{CH}$ & 0.54 \\
$\mathbf{2 , 4 - ( \mathbf { N O } _ { 2 } ) _ { 2 }}$ & $\mathrm{CH}$ & 0.52 \\
$\mathbf{3 , 5 - \mathbf { B r } _ { 2 }}$ & $\mathrm{N}$ & 0.22 \\
$\mathbf{H}$ & $\mathrm{N}$ & 12.1 \\
\hline
\end{tabular}

Figure 4. N'-substituted semicarbazonic derivatives of 5-nitrofurfural with tuberculostatic activity

mechanism of action. In in vivo trials, MXF's activity is comparable to that of isoniazide. Furthermore, combination of MXF and pyrazynamide is more effective than the combination of isoniazide, rifampicin and pyrazynamide [20].

Other authors have proved antituberculotic effect of $\mathrm{N}^{\prime}$-substituents of 5-nitrofurfural semicarbazone derivatives [21] (Figure 4).

The highest efficacy was related to the presence of electron accepting substituents such as chlorine atom or nitro group in the aryl fragment. In some cases, MIC values were lower compared to their equivalents of isoniazide, rifampicin and ciprofloxacin. Pyridil thiosemicarbazone derivatives proved to be more effective than their phenyl equivalents. These compounds eradicate slowly growing mycobacteria which could reduce therapy duration.

A number of scientific reports discuss tuberculostatic effect of monosubstituted bicyclic amides of heterocyclic compounds derivatives, both with one and two nitrogen atoms. One of the papers [22] presents a number of amide substituted indole derivatives (Figure 5).

Derivatives 3-5 with expanded cyclic systems from the amide group had the highest tuberculostatic effect. Their MIC values were lower compared to the MIC of isoniazide, TMC- 207 and PA- 824 [22]. Further-<smiles>[R]NC(=O)c1cc2c(C)cc(C)cc2[nH]1</smiles>

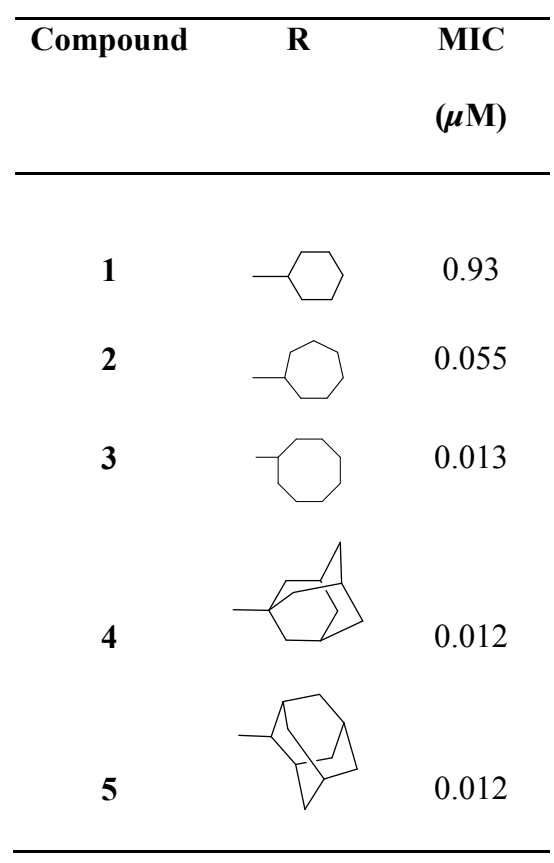

Figure 5. The MIC values for obtained heterocyclic compounds 
more, compounds 1, 2 and 3 had a significant effect against multi-drug-resistant XDR-Tb strains. What is extremely positive about this group of drugs is that the obtained substances are not toxic. These findings make the amide indole derivatives one of the most promising groups antituberculotic compounds.

Other authors [23] indicate a significant tuberculostatic effect of amide imidazo-[1,2-a]-pyridine derivatives (Figure 6).

The compounds having 4-(4-halogenohenoxy-substituted)benzyl substituent at amide nitrogene atom (7-9) had the lowest MIC values amounting to $\leqslant 0.006$ $\mu \mathrm{M}$. It has also been observed that the tuberculostatic effect of these compounds against drug resistant XDRTb strains in in vitro tests was ten times higher than that of PA-824 [23].

The obtained results of biological trials determined the following relationships between the structure of the study compounds and their tuberculostatic effect:

- the most advantageous factor is the presence of amide group in the second position of the bicyclic configuration;

- an expanded, three-dimensional lipophilic substituent is preferred by the amide $\mathrm{N}$ atom;

- N-1 atom in a heterocyclic system without any substituent and single substituted amide group $\mathrm{N}$ atom determine the manifestation of antituberculotic effect;

- presence of methyl groups in C-4 and C-6 positions of indole and C- 6 and C-7 positions of imidazopyridine increases activity of these compounds.
Yokokawa et al. have recently described a number of compounds having another bicyclic system of pyrazol[1,5-a]tetrahydropyrimidine in their structure [24]. A substance with the most profitable physicochemical properties and the best biological activity has been selected based on antituberculotic test results (Figure 7).

That is why it is very likely to become one of the tuberculostatic drugs in the nearest future.

Chemical synthesis in laboratory is not the only way of creating new antituberculotic drugs. Some of them are naturally found in the environment. For example, Caribbean Sea corals of Pseudopterogorgia elisabethae genus produce a group of pseudopterosins and pseudopteroxazoles. McCulloch et al. [25] submitted these natural substances to some chemical modifications and obtained a number of semisynthetic tuberculostatic substances with MIC values comparable to these of ethambutol, kanamycin, capreomycin and cycloserine. The derivative with a methyleneimidazol substituent had the best parameters, with its MIC value at $34 \mu \mathrm{M}$. Its molecular structure is shown in Figure 7.

The clofamizine derivatives are another group of very promising compounds - clofamizine belongs to the riminophenazine group, used until now in leprosy treatment [26]. Its efficacy against drug-resistant $M$. tuberculosis strains has been known since the 1960s. Unfortunately, the possibilities of putting clofamizine to common use in antituberculotic treatment are largely limited due to its lipophilicity and the common side effect consisting in skin pigmentation disorders. That<smiles></smiles>

\begin{tabular}{cccc}
\hline Compound & $\mathbf{R}^{1}$ & $\mathbf{X}$ \\
\hline $\mathbf{6}$ & $6-\mathrm{CH}_{3}$ & \\
$\mathbf{8}$ & $6-\mathrm{CH}_{3}$ & \\
9 & $7-\mathrm{CH}_{3}$ & & - \\
\hline
\end{tabular}

Figure 6 . The structures of some imidazo[1,2-a]pyridine derivatives 
is why clofamizine derivatives with C-2 pyridilamine substituent were synthesized, which were less lipophilic and had no adverse effect on the skin, while retaining the desired tuberculostatic effect (Figure 8) [26].

\section{Summary}

Despite the constantly developing prophylaxis and increase of public awareness, tuberculosis remains a huge health problem, both worldwide and in Poland. According to WHO data for 2011 [27], tuberculosis was the second (directly after AIDS) most common cause of death all over the world.

An increased number of cases of multidrug resistant tuberculosis (MDR-Tb) resistant to isoniazide and rifampicin is now being observed [1]. Cases of XDR-
$\mathrm{Tb}$, i.e. multidrug resistant tuberculosis with additional resistance to other important tuberculostatic drugs: fluoroquinolones, amikacin, kanamycin and capreomycin, have presented in many countries [28].

Each year, a number of researcher groups working at different research institutes and industrial laboratories make successful attempts at synthesizing new antituberculotic substances. Hopefully, among these new chemical combinations there will be compounds that will become modern antituberculotic drugs.

\section{References}

1. Protopopova M, Bogatcheva E, Nikonenko B, Hundert S, Einck L, Nacy CA. In search of new cures for tuberculosis. Med Chem. 2007;3:301-16.<smiles>Cc1ccc([C@@H]2C[C@H](C(F)(F)F)n3ncc(C(=O)NCc4ccc(F)cc4)c3N2)cc1</smiles>

Pyrazol $[1,5-a]$ tetrahydropirimidine<smiles>CC(C)=C[C@H]1C[C@H](C)[C@H]2CC[C@H](C)c3c2c1c(C)c1nc(Cc2cnc[nH]2)oc31</smiles>

\section{Pseudopteroxazole with methyleneimidazol substituent}

Figure 7. The structural formula of pirazol[1,5-a]tetrahydropyrimidine and pseudopteroxazole with imidazomethylene substituent

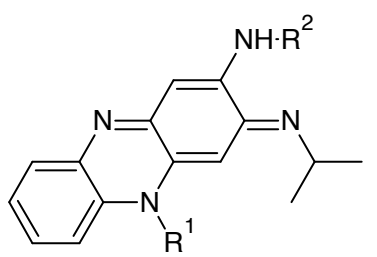

\begin{tabular}{llll}
\hline Compound & & ClogP & MIC $(\mu \mathrm{M})$ \\
\hline clofazimine & & \\
\hline
\end{tabular}

Figure 8. The structural formula of clofazimine and their active derivatives 
2. Laughon BE. New tuberculosis drugs in development. Curr Topics Med Chem. 2007;7(5):463-73.

3. Showalter HDH, Denny WA. A roadmap for drug discovery and its translation to small molecule agents in clinical development for tuberculosis treatment. Tuberculosis. 2008;88(Suppl. 1):3-17.

4. Żwawiak J, Zaprutko L. Pochodne imidazolu jako leki przeciwgruźlicze. Farm Współcz. 2012;5(4):192-9.

5. Andries K, Verhasselt P, Guillemont J, Gohlmann HW, Neefs JM, Winkler $\mathrm{H}$, et al. A diarylquinoline drug active on the ATP synthase of Mycobacterium tuberculosis. Science. 2005;307:223-7.

6. Matteelli A, Carvalho AC, Dooley KE, Kritski A. TMC207: the first compound of a new class of potent anti-tuberculosis drugs. Future Microbiol. 2010;5(6):849-58.

7. De Souza MVN, Pais KC, Kaiser CR, Peralta MA, Ferreira ML, Lourenco MCS. Synthesis and in vitro antitubercular activity of a series of quinoline derivatives. Bioorg Med Chem. 2009;17:1474-80.

8. Bogatcheva E, Hanrahan C, Nikonenko B, Samala R, Chen $\mathrm{P}$, Gearhart J, et al. Identification of new diamine scaffolds with activity against Mycobacterium tuberculosis. J Med Chem. 2006;49(11):3045-8.

9. Chen P, Gearhart J, Protopopova M, Einck L, Nacy CA. Synergic interaction of SQ109, a new ethylene diamine, with front-line antitubercular drugs in vitro. J Antimicrob Chemother. 2006;58:332-7.

10. Nikonenko BV, Protopopova M, Samala R, Einck L, Nacy CA. Drug Therapy of Experimental Tuberculosis (TB): Improved Outcome by Combining SQ109, a New Diamine Antibiotic, with Existing TB Drugs. Antimicrob Agents Chemother. 2007;51(4):1563-5.

11. SQ-109. Tuberculosis. 2008;88(2):159-61.

12. Makobongo MO, Einck L, Peek RM, Merrel DS. In Vitro Characterization of the Anti-Bacterial Activity of SQ 109 Against Helicobacter Pylori. PLoS One. 2013;8(7): e68917.

13. Jones PB, Parrish NM, Houston TA, Stapon A, Bansal NP, Dick JD, et al. A new class of anti-tuberculosis agents. J Med Chem. 2000;43:3304-14.

14. Parrish NM, Houston TA, Jones PB, Townsend C, Dick JD. In Vitro Activity of a Novel Antimycobacterial Compound, N-Octanesulfonylacetamide, and Its Effects on Lipid and Mycolic Acid Synthesis. Antimicrob Agents Chemother. 2001;45:1143-50.

15. Shinabarger D. Mechanism of action of the oxazolidinone antibacterial agents. Exp Opin Invest Drugs. 1999;8(8): 1195-202.

16. Alffenaar JWC, van der Laan T, Simons S, van der Werf TS, van de Kasteele PJ, de Neeling $\mathrm{H}$, et al. Susceptibility of Clinical Mycobacterium tuberculosis Isolates to a Potentially Less Toxic Derivate of Linezolid, PNU-100480. Antimicrob Agents Chemother. 2011;55(3):1287-9.

17. Schlunzen F, Pyetan E, Fucini P, Yonath A, Harms JM. Inhibition of peptide bond formation by pleuromutilins: the structure of the $50 \mathrm{~S}$ ribosomal subunit from Deinococcus radiodurans in complex with tiamulin. Mol Microbiol. 2004;54:1287-94.

18. Hu Y, Coates AR, Mitchison DA. Sterilizing activities of fluoroquinolones against rifampin-tolerant populations of Mycobacterium tuberculosis. Antimicrob Agents Chemother. 2003;47:653-7.

19. Nuermberger E, Tyagi S, Tasneen R, Williams KN. Almeida D, Rosenthal I, Grosset JH. Powerful Bactericidal and Sterilizing Activity of a Regimen Containing PA-824, Moxifloxacin, and Pyrazinamide in a Murine Model of Tuberculosis. Antimicrob Agents Chemother. 2008; 52(4):1522-4.

20. Paramasivan CN, Sulochana S, Kubendiran G, Venkatesan P, Mitchison DA. Bactericidal Action of Gatifloxacin, Rifampin, and Isoniazid on Logarithmic- and StationaryPhase Cultures of Mycobacterium tuberculosis. Antimicrob Agents Chemother. 2005;49:627-31.

21. Sriram D, Yogeeswari P, Dhakla P, Senthilkumar P, Banerjee D, Manjashetty TH. 5-Nitrofuran-2-yl derivatives: synthesis and inhibitory activities against growing and dormant mycobacterium species. Bioorg Med Chem Lett. 2009;19:1152-4.

22. Onayole OK, Pieroni M, Tipparaju SK, Lun S, Stec J, Chen G, et al. Preliminary Structure - Activity Relationships and Biological Evaluation of Novel Antitubercular Indolecarboxamide Derivatives Against Drug - Susceptible and Drug - Resistant Mycobacterium tuberculosis Strains. J Med Chem. 2013;56:4093-103.

23. Moraski GC, Markley LD, Cramer J, Hipskind PA, Boshoff $\mathrm{H}$, Bailey MA, et al. Advancement of Imidazo[1,2-a]pyridines with Improved Pharmacokinetics and nM Activity vs. Mycobacterium tuberculosis. ACS Med Chem Lett. 2013:4:675-9.

24. Yokokawa F, Wang G, Chan WL, Ang SH, Wong J, Ma I, et al. Discovery of Tetrahydropyrazolopyrimidine Carboxamide Derivatives As Potent and Orally Active Antitubercular Agents. ACS Med Chem Lett. 2013;4(5):451-5.

25. McCulloch MWB, Haltli B, Marchbank DH, Kerr RG. Evaluation of Pseudopteroxazole and Pseudopterosin Derivatives against Mycobacterium tuberculosis and Other Pathogens. Mar Drugs. 2012;10(8):1711-28.

26. Liu B, Liu K, Lu Y, Zhang D, Yang T, Li X, et al. Systematic Evaluation of Structure - Activity Relationships of the Riminophenazine Class and Discovery of a C2 Pyridylamino Series for the Treatment of Multidrug - Resistant Tuberculosis. Molecules. 2012;17:4545-59.

27. WHO Report 2011. Global Tuberculosis Control. World Health Organization. ISBN 9789241564380.

28. Yew WW. Managment of Multidrug-Resistant Tuberculosis and Extensively Drug-Resistant Tuberculosis: Current Status and Future Prospects. Kekkaku. 2011;86(1):9-16.

Correspondence adress: Justyna Żwawiak Department of Organic Chemistry Poznan University of Medical Sciences 6 Grunwaldzka Street 60-780 Poznań, Poland phone: +4861 8546670 fax: +48618546680 email: jzwawiak@ump.edu.pl 